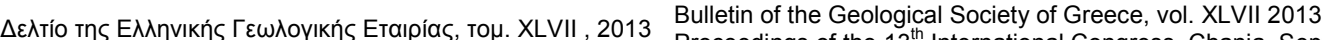

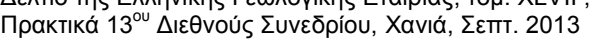

\title{
GIS AS AN EDUCATIONAL TOOL: MAPPING CULTURAL SITES IN GREEK SPACE-TIME
}

\author{
Galani L. ${ }^{1}$, Theodorakopoulou K. ${ }^{2}$, Skentos A. $_{K^{2}}{ }^{2}$ Kritikos G. ${ }^{2}$ and Pavlopoulos \\ $\mathrm{K}^{2}$ \\ ${ }^{1}$ National and Kapodistrian University of Athens, Faculty of Primary Education, \\ ligalani@pimedu.uoa.gr, \\ 2 Harokopio University, Department of Geography, \\ ktheodo@hua.gr,thanskentos@hua.gr,gkriti@hua.gr,kpavlop@hua.gr
}

\begin{abstract}
This paper deals with the cartographical presentation of cultural succession in Greek space-time associated with core concepts of geographic and historical education. The pedagogic value of this study is to develop five distinct skills: sense of time-scale, historical and geographic comprehension, spatial analysis and interpretation, ability to perform geo-historical research, and procedure of geohistorical decision-making.

The methodology is based on the calibration of a set of criteria for each cultural site that covers the topics of economy, geomorphology, society, religion, art and science. Further analysis of these data forms a geodatabase. In addition, palaeogeographic and historical maps of the cultural sites derived by the geodatabase provide information about temporal and spatial changes. As result, students will be able to develop a multidimensional and interdisciplinary approach, in order to reconstruct the evolution of the site.
\end{abstract}

Key words: geoarchaeology, palaeogeography, data base, education.

\section{Пєрі́ $\eta \psi \eta$}

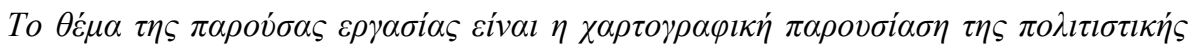

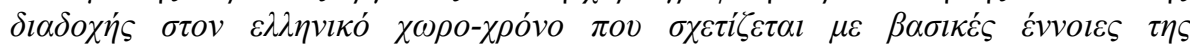

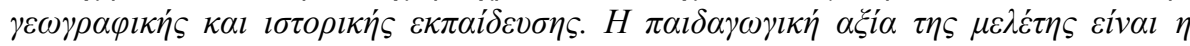

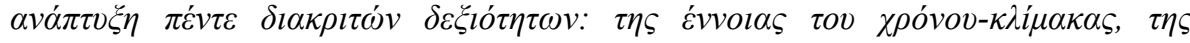

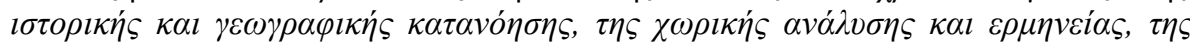

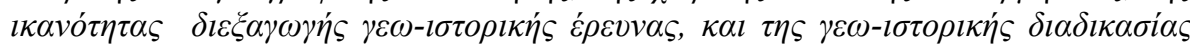
$\lambda \dot{\eta} \psi \eta \varsigma \alpha \pi \circ \varphi \alpha \dot{\sigma \varepsilon} \omega \nu$.

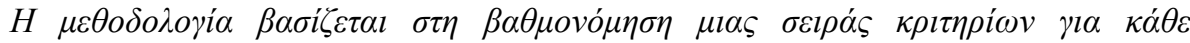

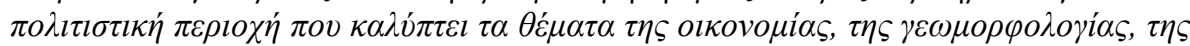

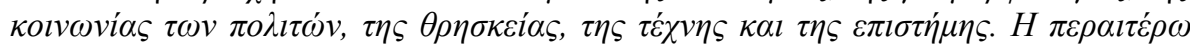

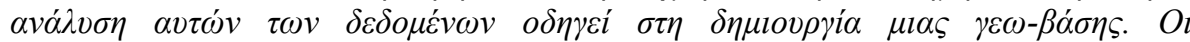

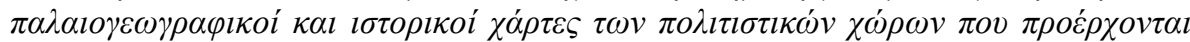

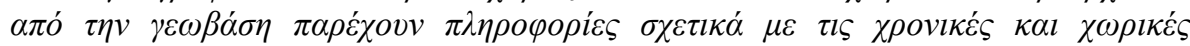

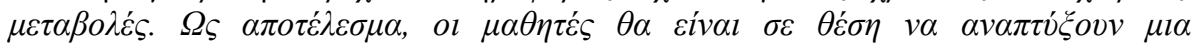

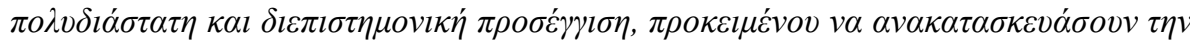

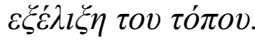

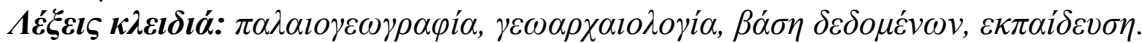

XLVII, No 2 - 1017 


\section{Introduction}

This paper reports a project taking place in the department of Geography of the Harokopio University, Athens, Greece. The project focuses on Digital Palaeogeography and specifically the cartographical presentation of cultural succession in Greek space and time (Choro-Chronos). What makes the subject of the program particularly important is its association with core concepts of geographic and historical education. The paper is structured in three different parts. The first consists of a review in other similar projects in the fields of Geography, History, Education and GIS. In the second part the authors describe the methodology, the tools they create and how tools are involved to the education. In the end of the paper the implications present authors opinion about the development of the project.

Geography and History in Greek school curriculum are two discrete subjects. Geography is focused on space, with increasingly complex definitions of what space itself is (Lefebvre, 1991). Most individuals define geography as a field of study that deals with maps. This definition is only partially correct. Spatial patterns play a central role in the subject. For the majority of its existence, Geography has used a spatial foundation to understand both the physical and human environment and how natural and human constructed phenomena are related to a spatial dimension.

On the other hand History has, as a central study, the human activity. The aim of the subject is to understand the past and to build a developing picture of how change has happened over time. In part the subject attempts to give a synthetic view of how humans, at a number of time scales, adapt and change.

History and Geography are disciplines which both attempt to understand the world around us through critical analysis of people and their environment. Time and space are inextricably linked, and cannot therefore be divorced and as Massey noticed '...time and space must be thought together... Thinking of time and space together does not mean they are identical (for instance in some undifferentiated four-dimensionality), rather it means that the imagination of one will have repercussions (not always followed through) for the imagination of the other and that space and time are implicated in each other.... Thinking about history and temporality necessarily has implications (whether we recognize them or not) for how we imagine the spatial.' (Massey, 2005).

Although at an academic level the approaches of humans and their environment have the potential for the building of a holistic understanding, at the school context (school history and school geography) the barriers of historical and geographical approaches still remain and the two subjects have different content and approaches. A range intersection of History and Geography seems to be Palaeogeography which can be defined as the study of geographical features at periods in the geological past and on the same time the understanding in a variety of contexts such as the study of physical landscapes, but also the study of human or cultural environments.

However, are we able to help students understand that 'time and space must be thought together' developing a learning resource to achieve this more holistic understanding of humans and their environment?

The answer lies in the field of technologies. In order to teach "thinking geographically" many organizations and individuals promote the use of GIS in K-12 geography education (Baker and White 2003; Ludwig et al. 2000; West 2003) According to Baker (2005), the integration of Geographic Information Systems (GIS) in schools could be a solution. GIS, as an instructional technology, has been used not only in the formal but also in informal education all over the world for more than fifteen years as well, in order to be approached significances such as the ecosystems, the demographic characteristics of places, the immigration, the natural destructions, etc. Moreover, through GIS students develop spatial analysis skills, a critic sense on spatial management and encourage them to contact research and to work in groups. GIS make students aware of the importance of geographic information on studding the past and on spatial management.

XLVII, No 2- 1018 
The development of Historical Geographic Information Systems (HGIS), over the past decade, has been a prospect to use the functionality of GIS systems to interrogate historical spatial data, for example old maps, census data, changing and evolving transport links, or population migrations.

In the U.S.A. there is also an initial attempt to make HGIS style resources open to school-level study. Historical Census Data developed by the University of Illinois at Chicago (Randinsky et al. 2008; GIS for History 2005-20011) was a project which - according to the instructors- make historical census data available to teachers and students in the form of on-line interactive data maps, displaying selected census data for each decade (1790-2000) on US maps at the county level.

\section{Methodology - Data Base}

\subsection{Objectives of the Project}

According to Vygotsky (1976) individuals make sense of the world around them by actively creating knowledge and understanding. The main scientific and technical objectives of the project are to:

- Understand that space and time need to be 'thought together', in order students to make use of models of spatial thinking,

- Identify that a GIS style platform would offer a critical medium through which the spatial thinking could be developed,

- Create an interactive platform to present spatio-temporal changes in Greece,

- Encourage generation of deep learning and critical analysis of geography and history through the spatio-temporal lens.

\subsection{Defining Criteria for the Geoarchaeological Sites}

Our scientific team determined some criteria for the selection of the most suitable archaeologicalhistorical sites. Among the criteria adopted for determining a particular period as a 'learning object' was the duration of its effects, the number of people affected by this, the perceived importance of the event by more people and the different manifestations of social space within the specific period. This will help students to form their own comprehensive mental map.

With this in mind, this research program involves archaeological sites and selected sites. Although it is addressed to the average reader, is seeking the awareness of the public to the basic methods of archeology. This is consistent with the view of Tilden who considers that the interpretation of material culture "should encourage the public to think alone and not telling him what to think".(Tilden, 1977).

Considering all the above theories on the concept of the importance of timing, in the first phase we defined some qualitative criteria for the selection sites:

1) Palaeogeography-natural geomorphic processes. The space is a dynamic system that is evolving and adapting continuously to changing influences. Man is part of the space and he intervenes actively in its formulation. Through the study of space and natural processes made at different times, it is possible to explore and highlight: a) the way in which people have adapted their lives to the topography and climate, b) how changes occurring in the natural environment affected the lives of people, c) the possible drastic changes done by people in the environment and ultimately their effects in everyday life.

2) Economic, social space (architectural, everyday objects): The study of material remains of the past, helps in the understanding and interpretation of economic, social, political and cultural structure of social groups that created them and the study and research of popular culture

XLVII, No $2-1019$ 
3) Sacred places-places of worship: The sacred places are inextricably tied to the organization of human life. Through religion people were expressed: building temples, carving statues, painting pictures, decorating buildings. Religion is not only a belief in a deity, but something deeper setting their lifestyle, the form of the family, the dietary habits, the social relations and the economy. The worship rituals characterize the integral part of life and culture of each period.

4)Science-technology: The use of technology by the human race began with the conversion of natural raw materials into simple tools. Both science and technology is a sign of progress and civilization.

5) Writing: Writing is a symbolic, visual language system log. Through the writings handed down from generation to generation, the language, the ideas, the habits of communities were transferred.

6) Networks-communication: The term of networks is very broad. It includes the necessary infrastructure for the development of cities or villages. We can distinguish from ancient period the transportation networks involving land roads and sea routes. These roads were also routes for trade, communication, economy, exchange of cultures, tastes, knowledge and language.

7) Residence: The time in space is reflected in the form of the material remains. The structure of houses, their architecture and the organisation of towns is reflecting the type of everyday life, the civilization and the organisation of societies.

\subsection{The Platform: Description and Architecture Design}

Further analysis of these data forms a geodatabase. The data base as a product of the process and as an educational tool, gives the ability to create documents, to organize and present the information, to investigate and analyze quantitative data to categorize and classify the information, based on specific criteria. In addition, palaeogeographic and historical maps of the sites derived by the geodatabase provide information about temporal and spatial changes.

The platform will contain spatial/mapped representations of different 'places' through a number of time slices. The maps which form this basic platform have tagged points, behind which exists a 'database' of information and other resources (ex. pictures, sketches, draws, representations, articles, scientific papers, etc.) which can be interrogated by users.

\subsection{Analyzing Changes in Conditions Through Time Using Digital Palaeography}

A good Geography and History lesson focuses on getting students think geographically and historically. However, how "thinking Geographically" and Historically can be effectuated in the classroom using the "Digital Palaeogeography platform"? Topics related to the geographic understanding of land change and land use change, are: the location of ancient cities and their growth through the time, the location of the temples and of the sacred places, the trade in Aegean Sea, the transportations in the mainland, etc.

The case study cited below presents an application of the project in the classroom. Let's suppose that students according to the curriculum have to study the topic of "Piracy in Aegean Sea".

Possible geographical questions to excite their curiosity are:

- "Do you think that piracy has existed in Greece from ancient time?"

- "If yes, where did pirates live?" (location)

- "How did they choose a place to keep safe their treasure?" (place)

- "What is it like in this place?" (conditions)

- "If you were a pirate, which place in Greece would you choose to settle? (region)

- "How is this place linked to other places?" (connections, links)

XLVII, No $2-1020$ 
- "How are the places you choose similar or different?" (comparison)

All these questions help students identify how the physical geography affected the settlement of islands by the pirates and generally how the geography of Greece influence where people settled and if Braudel's phrase "the islands of the central and eastern Mediterranean, gained a special importance when linked into strategic routes of commerce and defence" has a meaning.

From the movies, piracy is strongly connected to the Caribbean. Using their experiences, students can discuss and set criteria to choose a place where pirates might live.

Exploring the map, they find suitable locations, they write words describing what these places look like and they infer how these descriptions meet the criteria they set before. Data sources availability for each place including features interpreted from diverse data sources ex. historical topographic maps, satellite images, pictures and gravures, in conjunction with historical significance, determines how places that are mapped in the time periods, are connected to the piracy.

Their research using the maps and the database of the project demonstrate that:

1. Pirates using to work in Aegean Sea are faced with a characteristic series of choices, which depend on the character of the islands and the landscape, the volume of traffic, and the wealth of the communities. Piracy began soon after people first used water to carry trade goods from one place to another.

2. Merchant ships of the ancient world usually sailed close to land in going from one destination to another. Pirates chose to live along rocky shores, coves or inlets that provided shelter and kept them hidden from view, therefore it was easy for them to attack their "victims". These safe bases had several things in common: a) Close proximity to strategic economic value trade routes maritime shipping used, b) Isolated locations that discouraged pursuers from following,

3. Ancient pirate bases in Aegean Sea included islands such Milos, Crete, Andros, Syros, Rodes.

During this "trip" around the islands and the exploration of the piracy world, students may discover that at least one of the ports, Phalasarna, located in the middle of the west coast of Crete, was established far away from the sea. Why pirates choose this place? Did they move their ships to the land to keep them safe? That seems a good problem for them to solve.

Reading all the information from the database, students discover that the city of Phalasarna was already inhabited in the Middle Minoan period, while its development is depicted by the Archaic and Classical tombs discovered in the nearby area. In the middle of the 4th century, the city was at its peak. A port was constructed and city's strategic position in-between the Aegean - Egypt and Western - Eastern Mediterranean Sea crossroads thrust the city to issue coins and to develop naval trade. After the 2 nd century B.C. the port was used as a pirate den. The Romans destroyed the city in 67 B.C., most probably because of its turning to piracy.

Using the map and the ability of zoom in, students realise that the port of Phalasarna was established in an existing basin, which was reshaped. Access to the open sea was achieved by building a $100 \mathrm{~m}$ long canal from the port to the sea that was also functioning as a drainage work and kept it safe. Total annihilation occurred during the 4th century A.D., probably in 365 A.D., when the whole area rose by about $6.6 \mathrm{~m}$ due to a severe earthquake (figure 1).

Students through that information can explain why Phalasarna is pointed in inland. The buried of the city and the port by tectonic action, shows that landscapes change through time, sometimes slowly, other times violently (transition, change). The study of the geoarchaeology helps them to understand and to explain the strong connection between the landscape and the humans.

$\underline{\text { XLVII, No } 2-1021}$ 


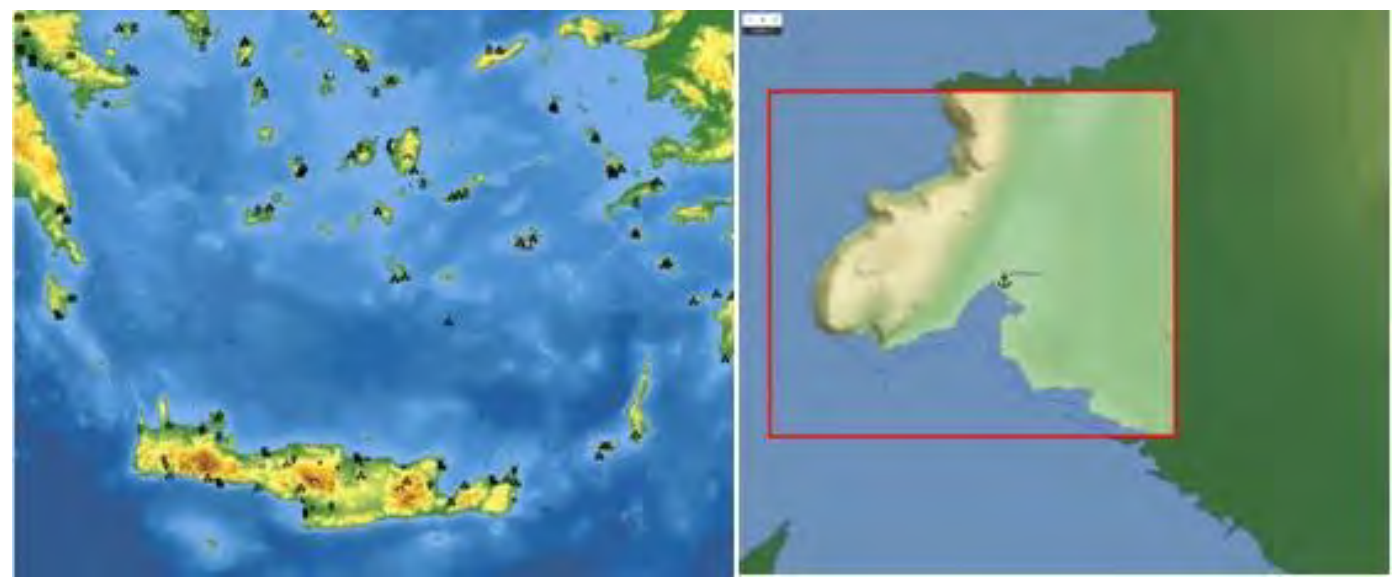

Figure 1 - The map of the project. Phalasarna's coastline now and then (zoom in) is presented in the second picture.

\subsection{Pedagogic Value of the Platform}

The pedagogic value of this project lies in the development of five distinct skills:

a) Sense of time and scale which is significant to the Chronological thinking: Students will be able to distinguish between past, present, and future geological and historical time. Time scale provides the mental map for organizing humans' thought. Having a strong sense of time thought a time line data presentation - ex. of when geological or historical events occurred and in what order- students should be able to examine relationships and to explain the causality among those events. Students should also be able to analyze patterns of succession, for example, the networks of trade and communication in Aegean Sea over the time.

b) Geographic and Historical Comprehension: Maps, photographs, paintings, documents and information presented in the geo-historical narrative/information of the database help students to obtain or clarify information on the geographic setting in which a temple or a colony was situated or a historical event occurred. They can also notice the relative and absolute location of the features (places, monuments, temples, etc.) they study, the distances and directions between them, the natural and man-made features of the place, and critical relationships in the spatial distributions of those features and the event occurring there.

c) Analysis and interpretation of geographic space: GIS analysis is a process which helps students to see patterns and relationships between features and to interpret the geographical data. They can find out why things are where they are, how things are related and how changes happened through the time and to create new information which helps them to gain a deeper understanding of places. Through the GIS palaeogeographic map, students should be to analyze cause-and-effect relationships bearing in mind multiple causation including the importance of the individual in changes, the influence of ideas and beliefs and the role of chance.

d) Ability to perform geo-historical research: Students through digital palaeogeography will be encouraged to develop and implement a research action plan following specific steps such as: to identify the aim/purpose of the investigation, to generate a number of questions to be addressed by the investigation, to collect and use primary and secondary data, to decide which primary and secondary data are needed to answer the questions, to propose individual or team action in response to the research findings.

e) Analysis interpretation of geo-historical decision-making: Issue-centered analysis and decision-making activities place students at the center of geo-historical dilemmas and problems faced at critical moments in the past and the near-present. Students evaluate 
alternative courses of action, keeping in mind the available information, the interests of those affected by the decision, and the long- and short-term consequences of each.

As result, students will be able to develop multidimensional, evidence driven approach, in order to answer questions and to "rebuild" the historical "Chorochrono" through interdisciplinary and methodological pluralism which characterizes the modern geography, suppressing the barriers between the sciences.

\section{Implications}

The project will be completed by September 2013. According to the researchers of the project, roaming in Greece with the help of the GIS platform, is an alternative but very important "tool" for the Geography lesson, that allows students to explore the earth at a potential way, and to participate in the learning with an amusing and simultaneously communication way.

Students will be able to develop a multidimensional and interdisciplinary approach, in order to reconstruct the evolution of the site. In this way, historical analysis involves an explicit spatial element, and makes the 'thinking together' of space and time concrete.

In the training level, such "tools" as Digital Palaeogeography can improve the process of learning because:

- They can be used to approach scientific and land management questions by analyzing maps for the details they contain

- They help the students to shape more complete intellectual picture of space, strengthening a more catholic approach as they provide the possibility of analysis and composition of space

- They provide the possibility of treatment of each information, with greater occasion of acceptance or rejection that the students develop critical attitude against the knowledge

- They help in the cross-correlation of knowledge

- They contribute in the disengagement from the school book or in the different use of it and

- They promote the spatial thinking through processes and activities that were reported.

\section{References}

Baker and White 2003. The effects of G.I.S. on students' attitudes, self-efficacy, and achievement in middle school science classrooms, Journal of Geography, 102, 243-254.

GIS for History, We the People project, University of Illinois at Chicago, online at http://www.gisforhistory.org/

Lefebvre H. 1991. The production of space, Blackwell, Oxford.

Ludwig S. G. 2000. GIS in Schools, Audet H. R., ESRI.

Massey, D., 2005. For Space, London, Sage.

Radinsky Johnston and Ryan 2008. Bringing Historical Census Data Alive: Historical inquiry with Geographic Information Systems, University of Illinois at Chicago, online article at http://www.uic.edu/educ/bctpi/historyGIS/NEHRadinsky03narrative.pdf .

Tilden 1977. Interpreting our heritage, Oxford University Press.

Vygotsky L.S. 1978. Mind in Society. Cambridge, MA: Harvard University Press.

West B. 2003. Student attitudes and the impact of GIS on thinking skills and motivation, Journal of Geography, 102/(6), 267-274. 